\title{
Paediatric rhabdomyosarcoma: MyoD1 demonstration in routinely processed tissue sections using wet heat pretreatment (pressure cooking) for antigen retrieval
}

\author{
M E Engel, S C E Mouton, $M$ Emms
}

\begin{abstract}
Aims-To investigate wet heat pretreatment (pressure cooking) as a means of antigen retrieval for demonstration of MyoD1 in paraffin wax embedded tissue.

Methods-Routinely processed tissue sections of transmission electron microscope confirmed cases of rhabdomyosarcoma were stained immunohistochemically with the MyoD1 antibody. Antigen retrieval was achieved by wet heat pretreatment of the tissue sections.

Results-MyoD1 was stained successfully in all seven cases. The protein was localised to nuclei and cytoplasm depending on the type of tumour cell.

Conclusions-Wet heat pretreatment for antigen retrieval from routinely processed tissue sections permits excellent subsequent immunostaining for MyoD1 in rhabdomyoblasts.

(f Clin Pathol 1997;50:37-39)
\end{abstract}

Keywords: rhabdomyosarcoma; MyoD1; wet heat processing.

Rhabdomyosarcoma is one of the so-called small round blue cell tumours of childhood. ${ }^{1}$ The definitive diagnosis of rhabdomyosarcoma is based on specific transmission electron microscopic (TEM) features, and the immunohistochemical results of a panel of markers. ${ }^{2}$ MyoD1 is one of the products expressed early in the lineage of skeletal muscle differentiation. ${ }^{3-6}$ The presence of this protein in neoplastic cells is regarded as definitive evidence of rhabdomyoblastic differentiation. ${ }^{2} 78$

Wet heat processing (pressure cooking) has recently been described as a means of antigen retrieval in paraffin wax embedded tissue sections. ${ }^{9-11}$ Wet heat processing has been used in conjunction with a variety of antisera, and is superior in re-exposing epitopes masked by fixation. ${ }^{11}$

To date, MyoD1 has been demonstrated successfully in frozen tissue sections, ${ }^{8}$ as well as in paraffin wax sections subjected to microwave pretreatment for antigen retrieval. ${ }^{4}$ The application of wet heat processing in the demonstration of MyoD1 in paraffin wax sections has not been reported previously. In the present study, we investigated the suitability of pressure cooking as a means of antigen retrieval in demonstrating the presence of MyoD1 in rhabdomyoblasts in routinely processed tissue sections from TEM confirmed cases of rhabdomyosarcoma.

\section{Methods}

All material used in this study was obtained from the archives of the Department of Histopathology, Red Cross Children's Hospital, University of Cape Town, Cape Town. The seven cases presented in this study span 10 years from 1985 to 1994, and were all confirmed as rhabdomyosarcoma by TEM according to the typical and minimal ultrastructural criteria required for this diagnosis. ${ }^{2}$ Tissue samples were fixed in $10 \%$ phosphate buffered formalin, $\mathrm{pH}$ 7.4, for 24-48 hours depending on the size of the specimen. Sections were processed using the Shandon 2LE automated tissue processor. Case 6 had additional routinely processed tissue which had been fixed in B5 fixative. A neuroblastoma, confirmed by TEM, was included as a negative control. The histopathological types of rhabdomyosarcoma and the origin of the tissue specimens are given in table 1.

Sections from routinely processed tissues and the single case of tissue fixed in B5 fixative were mounted on slides coated with 3-aminopropyltriethoxysilane (APES) (Sigma). Sections were then dried at $56^{\circ} \mathrm{C}$ for one hour, dewaxed using xylene, dehydrated through a descending alcohol series, and collected in distilled water. Sections not to be pressure cooked (negative control for the technique) were prepared simultaneously.

For the wet heat processing procedure, 1.5 litres of $0.01 \mathrm{M}$ sodium citrate buffer, $\mathrm{pH} 6.0$, was brought to the boil (without sealing the lid) in a stainless steel 5.5 litre capacity domestic pressure cooker (Tedelex) heated on an electric hot plate (General Electric). The slides, in metal racks, were lowered into the boiling sodium citrate buffer, after which the pressure cooker was sealed and brought to full pressure of about $100 \mathrm{kPa}$, at which point timing began. The optimal time was established previously as 80 seconds. The pressure cooker, still sealed, was then placed under running cold water until the pressure indicator dropped to its original position. On removal from the pressure cooker, the slides were immediately immersed in cold distilled water and then transferred to Tris buffered saline (TBS) $(0.05 \mathrm{M}$ Tris $/ \mathrm{HCl}, \mathrm{pH}$ 7.6, 0.15 M NaCl). 
Table 1 Clinical and histopathological data

\begin{tabular}{llll}
\hline Case number & Diagnosis & Tissue & Site \\
\hline 1 & Embryonal & Lymph node & Not supplied \\
2 & Embryonal & Soft tissue & Neck \\
3 & Embryonal & Lymph node & Neck \\
4 & Not specified & Skeletal muscle & Right calf \\
5 & Embryonal & Tumour & Left thigh \\
6 & Alveolar & Tumour & Soft palate \\
7 & Embryonal & Tumour & Right testis \\
$8^{\star}$ & Neuroblastoma & Soft tissue & Nasopharyn \\
\hline
\end{tabular}

$\star$ Negative control.

Table 2 MyoD1 localisation in rhabdomyoblasts and control tissue after wet heat processing

\begin{tabular}{llllll}
\hline & \multicolumn{2}{l}{ Rhabdomyoblast } & & \multicolumn{2}{l}{ Small round blue cell } \\
\cline { 2 - 3 } \cline { 5 - 6 } Case number & Nuclei & Cytoplasm & & Nuclei & Cytoplasm \\
\hline 1 & Negative & Positive & & Positive & Negative \\
2 & Negative & Positive & & Positive & Negative \\
3 & Negative & Positive & & Positive & Negative \\
4 & Negative & Positive & & Positive & Negative \\
5 & Negative & Positive & & Negative & Negative \\
6 & Negative & Positive & & Negative & Negative \\
7 & Negative & Positive & & Positive & Negative \\
$8^{\star}$ & Negative & Negative & & Negative & Negative \\
\hline & & & & &
\end{tabular}

^Negative control. dermal tumours. ${ }^{8}$ Correct histopathological diagnosis is very important for subsequent treatment and prognosis. Panels of various combinations of both mono- and polyclonal antibodies are used with the view to eliminating some diagnoses, and to confirm or suggest the most likely diagnosis. However, some antibodies lack specificity and sensitivity when applied to the small round blue cell tumours, mostly because of the absence of differentiation in the neoplastic cells. The presence of MyoD1 is accepted as diagnostic evidence of rhabdomyosarcoma, being absent in other childhood solid tumours. ${ }^{8}$ MyoD1 is a nuclear phosphoprotein and the product of the MyoDl gene on chromosome $11 \mathrm{p} .^{3-5}$ This gene is a member of the MyoD family of myogenic regulatory genes which express DNA binding proteins that control the initial genetic events leading to the transcription of DNA sequences encoding myogenic proteins, such as desmin, creatinine kinase and myosin. ${ }^{4612}$

Fixing tissue in formalin and embedding it in paraffin wax can mask antigens, and thus some kind of unmasking procedure is required. Enzymatic digestion has been used by many laboratories for this purpose. Microwave heating has been used to retrieve antigen ${ }^{13}{ }^{14}$ and

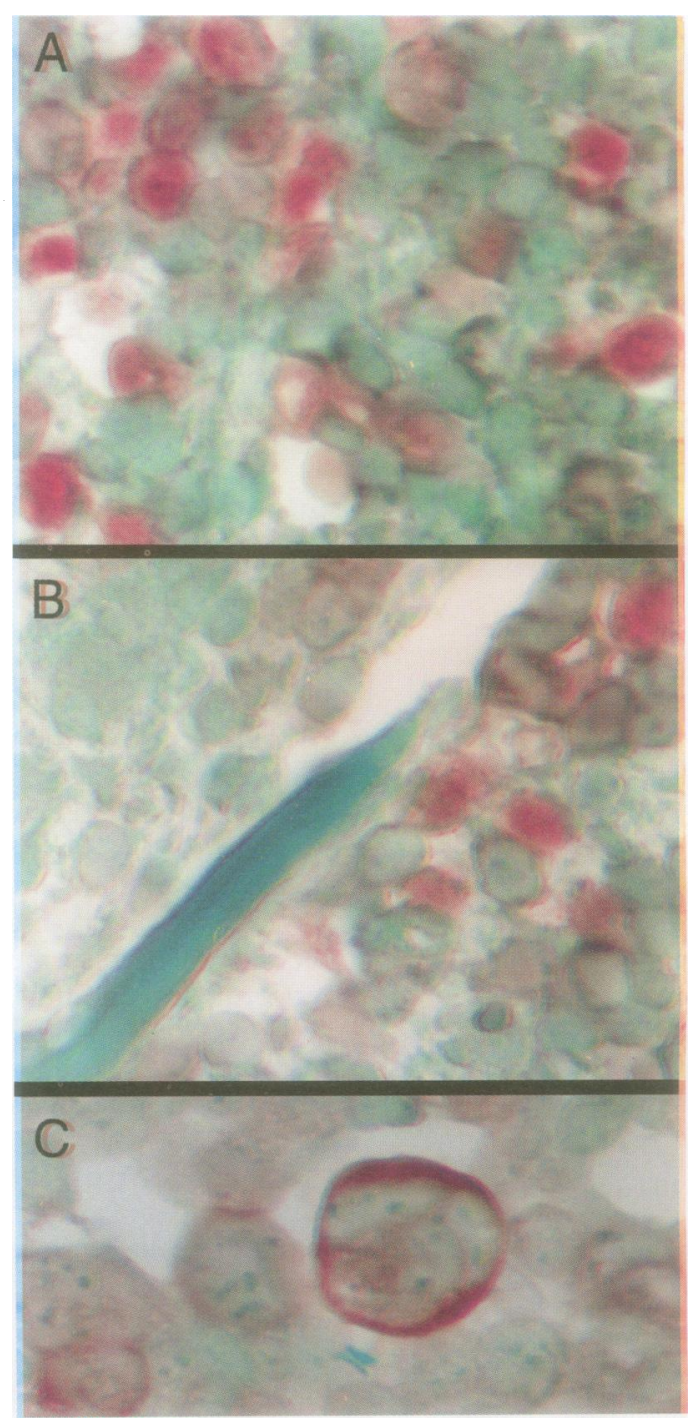

Figure 1 MyoD1 staining in rhabdomyoblasts. $(A)$ and $(B)$ Nuclear staining. Note the absence of staining in skeletal muscle cells in (B). (C) Cytoplasmic staining.

\section{Discussion}

Small round blue cell tumours of childhood include a variety of neoplasms, such as non-Hodgkin's lymphoma, neuroblastoma, rhabdomyosarcoma, and primitive neuroecto-
Sections were stained immunohistochemiin a moist chamber. After washing temperature for 15 minutes in Dako normal goat serum diluted 1 in 2 with TBS, followed MyoD1 (Novacastra Laboratories, UK) monowith TBS. After washing, the sections were incubated at room temperature for 20 minutes diluted 1 in 300 with TBS. After washing, sections were incubated at room temperature prepared as described by the manufacturer fuchsin substrate was used as the chromogen and $1 \%$ light green as the counterstain. The sections were mounted in glycerol $\times 10$ and $\times 40$ objectives, MyoD1 immunostain ing was sought within the small round blue were regarded as MyoD1 positive when there was diffuse staining of either the nucleus ${ }^{5}$ or the

Results

Using the wet heat processing method of antiMyoD1 stained all seven rhabdomyosarcomas. Signal visualisation was optimal and the protein could be readily localised to the nuclei showed better preservation of cellular details facilitating cellular localisation of the protein The neuroblastoma tissue sections did not file is shown in table 2. 
although a microwave processor has been designed specifically for laboratory use, many workers report success using a domestic microwave oven. ${ }^{15}$ The technique is quick, reproducible, cost efficient, and facilitates antigen detection in tissues by markers which previously worked only in frozen tissue. ${ }^{15}$ MyoDl has been detected successfully in microwave pretreated paraffin wax sections. ${ }^{4}$ However, the microwave technique is not without drawbacks. These include hot and cold spots in domestic ovens which result in batch inconsistencies and less than acceptable antigen recovery. ${ }^{11}$ The number of sections accommodated is limited and constant monitoring is needed during the procedure; alteration in nuclear morphology has also been claimed. ${ }^{16}$

Wet heat processing has emerged as an alternative to overcome these drawbacks. It is similar to microwave pretreatment, both being dependent on superheating to denature the protein and rupture some of the aldehyde crosslinks. ${ }^{10}$ Only a proportion of the nuclei of the poorly differentiated rhabdomyoblastic cells in our material stained positively (figs $1 \mathrm{~A}$ and $1 \mathrm{~B}$ ). This phenomenon may be related to the findings of other workers that MyoD1 gene expression is down regulated when other members of the MyoD family are up regulated-for example, myogenin and myf-5. ${ }^{17}$ Positive cytoplasmic immunostaining for MyoD1 has been reported previously, but no explanation has been forthcoming. ${ }^{8}$ In our study, cytoplasmic immunostaining was noted specifically in large polygonal, often multinucleated, neoplastic cells (fig 1C). Members of the MyoD gene family activate their own transcription and transactivate the transcription of other members of the family. The antagonism between growth factor inducible immediate early gene products and those of the MyoD family can be overcome by the excess production of, for instance, MyoD $1 .{ }^{18}$ As an excess of MyoDl can apparently cause transactivation of myogenin, present in the latter stages of myogenesis, ${ }^{3}$ it is conceivable that nuclear MyoD1 is replaced by nuclear myogenin, and that excess MyoD1 appears temporarily in the cytoplasm of the bi- and multinucleated syncytia.
In conclusion, wet heat processing is an alternative method of antigen retrieval in routinely processed paraffin wax sections. Using this method, MyoD1 can be stained readily, thereby facilitating the diagnosis of rhabdomyosarcoma in small round blue cell tumours of childhood.

1 Carter RL, McCarthy KP. Divergent differentiation in round-cell tumours of soft tissues: an interim appraisal. Histopathology 1993;23:93-7.

2 Tsokos M. The diagnosis and classification of childhood rhabdomyosarcoma. Semin Diagn Pathol 1994;11:26-38.

3 Dias P, Dilling M, Houghton P. The molecular basis of skeletal muscle differentiation. Semin Diagn Pathol 1994;11:314.

4 Tsang WYW. MyoD1: The skeletal muscle differentiation regulator gene. Adv Anat Pathol 1994;1:173-5.

5 Wesche WA, Fletcher CDM, Dias P, Houghton PJ, Parham DM. Immunohistochemistry of MyoD1 in adult pleomorphic soft tissue sarcomas. Am f Surg Pathol 1995;19:261-9.

6 Wientraub $H$, Davis $R$, Tapscott $S$, Thayler $M$, Krause $M$, Benezra B, et al. The MyoD gene family: Nodal point during specification of the muscle cell lineage. Science ing specification

7 Tonin PN, Scrable H, Shimada H, Cavenee WK. Musclespecific gene expression in rhabdomyosarcomas and stages of human fetal skeletal muscle development. Cancer Res 1991;51:5100-16.

8 Dias P, Parham DM, Shapiro DN, Weber BL, Houghton PJ. Myogenic regulatory protein (MyoD1) expression in childhood solid tumours. Am $\mathcal{F}$ Pathol 1990;137:128-91.

9 Bankfalvi A, Navabi H, Bier B, Bocker W, Jasani B, Schimd $\mathrm{KW}$. Wet heat pretreatment for antigen retrieval in diagnostic immunohistochemistry. $\mathcal{F}$ Pathol 1994;174:223-8.

10 Norton JA, Jordan S, Yeomans P. Brief, high-temperature heat denaturation (pressure cooking): A simple and effective method of antigen retrieval for routinely processed tissues. F Pathol 1994;173:371-9.

11 Miller K, Auld J, Jessup E, Rhodes A, Ashton-Key M. Antigen unmasking in formalin-fixed routinely processed paraffin wax-embedded sections by pressure cooking: A comparison with microwave oven heating and traditional methods. Adv Anat Pathol 1995;2:60-4.

12 Parham DM. The molecular biology of childhood rhabdomyosarcoma. Semin Diagn Pathol 1994;11:38-46.

13 Shi SR, Key ME, Kalra KL. Antigen retrieval in formalin-fixed, paraffin-embedded tissues: an enhancement method for immunohistochemical staining based on microwave oven heating of tissue sections. $\mathcal{f}$ Histochem Cytochem 1991;39:741-8.

14 Cattoretti G, Suurmeijer AJH. Antigen unmasking on formalin-fixed paraffin-embedded tissues using microwaves: A review. Adv Anat Pathol 1995;2:2-9.

15 Ceuvas EC, Bateman AC, Wilkins BS, Johnson PA Williams JH, Lee AHS, et al. Microwave antigen retrieval in immunocytochemistry: a study of 80 antibodies. $\mathcal{f}$ Clin Pathol 1994;47:448-52.

16 Powell C. Pressure cooking retrieves "lost" antigens in tissue sections. Wet heat pretreatment for antigen retrieval in diagnostic immunohistochemistry. Human Exp Toxicol 1995;14:465-6.

17 Peterson CA, Gordon H, Hall ZW, Paterson BM, Blau HM. Negative control of the helix-loop-helix family of myogenic regulators in the NFB mutant. Cell 1990;62:493-502.

18 Bengal E, Ransone L, Scharfmann R, Dwarki W, Tapscott S, Wientraub $\mathrm{H}$, et al. Functional antagonism between c-Jun and MyoD proteins: A direct physical association. Cell 1992;68:507-19. 